\title{
SISTEMAS CONSORCIADOS DE AVEIA PRETA E ERVILHACA COMUM COMO COBERTURA DE SOLO E SEUS EFEITOS NA CULTURA DO MILHO EM SUCESSÃO(1)
}

\author{
C. G. BORTOLINI (2), P.R.F.SILVA(3) \& G. ARGENTA ${ }^{(4)}$
}

\begin{abstract}
RESUMO
Com o aumento do cultivo do milho no sistema plantio direto (SPD), várias espécies vegetais de inverno estão sendo avaliadas, visando à obtenção de uma cobertura de solo que beneficie o mi l ho cultivado em sucessão e o SPD. O objetivo deste trabalho foi avaliar o efeito de três densidades de semeadura de aveia preta e ervilhaca comum em sistemas consorciados e em cultivos isolados e de três níveis de adubação nitrogenada (zero, 60 e $160 \mathrm{~kg} \mathrm{ha}^{-1}$ ) aplicados em cobertura sobre a cultura do milho em sucessão. 0 experimento foi realizado em campo na Estação Experimental Agronômica da UFRGS em Eldorado do Sul (RS), no ano agrícola 1998/99. O rendimento total de matéria seca da cobertura de solo foi si mi lar entre os sistemas consorciados de aveia e ervilhaca e os cultivos isolados. $\mathrm{O}$ aumento da dose de $\mathrm{N}$ aplicada no milho e o incremento da proporção de sementes de ervilhaca no consórcio da cobertura de solo elevaram a quantidade de $\mathbf{N}$ acumulado por planta de mi lho. Na produtividade de grãos de mil ho, percebeu-se interação de doses de $\mathbf{N}$ aplicadas e sistemas de cobertura de solo. Sem aplicação de $\mathrm{N}$, houve aumento de $321 \mathrm{~kg} \mathrm{ha}^{-1}$ na produtividade de grãos, para cada $10 \%$ de substituição de aveia por ervilhaca nos sistemas de consórcio. Com $60 \mathrm{~kg} \mathrm{ha}^{-1}$ de $\mathrm{N}$, a resposta foi quadrática; com $160 \mathrm{~kg} \mathrm{ha}^{-1}$, não houve efeito das coberturas de solo no inverno sobre a produtividade de grãos. A produtividade de grãos de milho cultivado em sucessão à aveia em cultivo isolado ou em consórcio com ervilhaca aumentou linearmente com o aumento da dose da adubação nitrogenada; em sucessão à ervilhaca em cultivo isolado, não houve resposta do milho à adubação nitrogenada.
\end{abstract}

Termos de indexação: plantio direto, Avena strigosa, Vicia sativa, produtividade de milho, nitrogênio.

(1) Recebido para publicação em fevereiro de 2000 e aprovado em julho de 2000.

(2) Mestrando em Fitotecnia na Universidade Federal do Rio Grande do Sul - UFRG. Av. Bento Gonçalves 7712, Caixa Postal 776, CEP 91540-000 Porto Alegre (RS).

(3) Professor Adjunto do Departamento de Plantas de Lavoura da UFRGS. Bolsista do CNPq. E-mail: plantas@vortex.ufrgs.br

(4) Doutorando em Fitotecnia da UFRGS. Bolsista do CNPq. 


\title{
SUMMARY: INTERCROPPED BLACK OAT AND COMMON VETCH AS SOIL COVER AND THEIR EFFECT ON CORN
}

\begin{abstract}
With the increase of corn cultivation under the no-tillage system, various cover crop species have been evaluated to obtain a soil cover that benefits corn under succession and no-tillage. The objective of this work was to evaluate the effect of three sowing densities of black oat (Avena strigosa Scheig) and common vetch (Vicia sativa) in associated crops and as isol ated crops and three levels of nitrogen fertilization $(\mathrm{N})$, applied on corn $(0,60$ and $160 \mathrm{~kg} \mathrm{ha}^{-1}$ of N). Dry matter yield of thecover crop species was si milar in associated systems and as isolated crops. The increase in the amount of $\mathrm{N}$ applied and the increase in the proportion of common vetch seeds in the associated systems increased the amount of $\mathrm{N}$ accumulated by corn plants. Therewas no interaction between theamount of $\mathrm{N}$ appl ied and thesoil cover systems for corn grain yield. Without $\mathrm{N}$ fertilization, corn grain yi el d increased $321 \mathrm{~kg} \mathrm{ha}^{-1}$ for each $10 \%$ of substitution of oat for common vetch in the associated systems. With $60 \mathrm{~kg} \mathrm{ha}^{-1}$ of $\mathrm{N}$, the response was quadratic. With the $160 \mathrm{~kg} \mathrm{ha}^{-1}$ of $\mathrm{N}$, there was no effect of soil cover on corn grain yield. Grain yield of corn cultivated after oat as isolated crop or associated with common vetch increased linearly with theincrease of theamount of $\mathrm{N}$ fertilizer applied in corn. Under succession, using common vetch as an isolated crop, there was no response of corn grain yield to $\mathrm{N}$ fertilization.
\end{abstract}

Index term: no-tillage, Avena strigosa, Vicia sativa, corn yield, nitrogen.

\section{INTRODUÇÃO}

Apesar da grande área cultivada com milho no Brasil sua produtividade média é baixa, em razão de diversos fatores, dentre os quais se destacam as deficiências nutricionais, sobretudo de nitrogênio, que é o nutriente que mais freqüentemente limita a produtividade de grãos. Para obter altas produtividades de grãos, são necessárias el evadas quantidades de $\mathrm{N}$, fazendo com que o custo do fertilizante seja, em muitos casos, fator limitante à potencialização da produtividade da cultura.

A utilização de espécies legumi nosas em cobertura de sol o no inverno aumenta a disponibilidade de $\mathrm{N}$ no sistema e sua absorção pela planta e, conseqüentemente, a produtividade de grãos de milho cultivado em sucessão. A quantidade de $\mathrm{N}$ fornecido pelas espécies leguminosas de inverno pode chegar a $220 \mathrm{~kg} \mathrm{ha}^{-1}$ (Monegat, 1991).

Trabalhos realizados por Muzilli et al. (1983) mostraram que produtividade de grãos de milho semeado após leguminosas foi superior a $8 \mathrm{t} \mathrm{ha-1}$, não sendo influenciada pela adubação nitrogenada aplicada à cultura. Apesar destas vantagens, a utilização de legumi nosas como espécies antecessoras ao milho é pequena, por apresentarem maior custo em relação às gramíneas, por terem desenvolvimento inicial lento e, principalmente, pela rápida decomposição de seus resíduos (Sá, 1996).

Por outro lado, resíduos de espécies gramíneas, como aveia preta, apresentam baixa taxa de decomposição, o que determina mel hor proteção do sol o durantetodo ociclo do milho. Além disto, fatores, tais como: rusticidade, facilidade na aquisição de sementes e na instalação do cul tivo (Sá, 1997), rápido crescimento inicial (Da Ros \& Aita, 1996) e alto rendimento de matéria seca fazem com que a aveia preta seja a espécie mais utilizada como cobertura de solo no outono-inverno do sul do Brasil (Aita, 1997). A desvantagem do uso de gramíneas como cobertura de sol o está relacionada com a deficiência de $\mathrm{N}$ que pode provocar nos estádios iniciais de desenvolvimento do milho. No processo de decomposição da palha, a biomassa microbiana do solo, ao imobilizar o N, diminui a sua disponibilidade para o milho (Sangoi et al., 1999), podendo causar deficiência de N eredução da produtividade de grãos.

As diferentes características apresentadas pelas coberturas de sol o no Sistema Plantio Direto (SPD) torna difícil a recomendação deuma espécie quereúna somente aspectos desejáveis. A idéia de consorciação de espécies leguminosas e gramíneas surgiu para se obter cobertura de solo mais próxima da ideal, trazendo benefícios à produtividade de grãos do milho e ao SPD. Os sistemas consorciados podem acarretar eficiente cobertura vegetal no solo (Derpsh, 1984) emaior recidagem denutrientes, principalmente de N, no caso das leguminosas (Heinzmann, 1985).

É recomendável ebenéfico queseutilizem espécies de decomposição rápida de resíduos em associação com as de decomposição mais lenta (M onegat, 1991). Deste modo, o consórcio com leguminosas e gramíneas pode determinar a formação de uma cobertura de resíduos com características favoráveis 
não só à proteção do solo, principalmente pela presença de resíduos de gramíneas, mas também à nutrição do milho, pelo maior aporte de N propiciado pelas leguminosas.

Este trabal ho teve como objetivo avaliar o efeito de diferentes proporções de sementes de aveia preta e ervilhaca comum consorciadas e de seus cultivos isolados sobre a cultura do milho em sucessão, utilizando três níveis de adubação nitrogenada.

\section{MATE RIAL E MÉTODOS}

O trabalho foi realizado em campo na Estação Experimental Agronômica, da UniversidadeF ederal do Rio GrandedoSul, em Eldorado doSul, localizada na região fisiográfica da Depressão Central do estado do Rio Grande do Sul, no ano agrícola 1998/99. O solo da área experimental pertence à unidade de mapeamentoSãoJ erônimo, sendo classificado como Argissolo Vermelho Distrófico típico (EMBRAPA, 1999).

A análise do solo, realizada antes da instalação do experimento, indicou os seguintes valores: teor deargila de $28 \%$, pH 5,2 eteores de fósforo, potássio e matéria orgânica de $16 \mathrm{mg} \mathrm{dm}^{-3}, 134 \mathrm{mg} \mathrm{dm}^{-3} \mathrm{e}$ $26 \mathrm{~g} \mathrm{~kg}^{-1}$, respectivamente. A área experimental vinha sendo cultivada em sistema de semeadura direta há quatro anos. Nos cultivos de inverno, a espécie utilizada foi sempre a aveia preta e, nos cultivos de verão, nas safras 1997/98, 1996/97, 1995/ 96 e 1994/95, as culturas foram milho, milho, soja e milho, respectivamente.

Os tratamentos constaram de três níveis de adubação nitrogenada $\left(0,60\right.$ e $160 \mathrm{~kg} \mathrm{ha}^{-1}$ de $\left.\mathrm{N}\right)$, aplicados no milho cultivado em sucessão às coberturas de solo, e de três combinações de densidades de plantas deaveia preta (Avena strigosa Scheib) (Av) eervilhaca comum (Vicia sativa L.) (Er), em sistemas consorciados e em cultivos isolados como cobertura de sol o: $100 \% \mathrm{Av} ; 67 \% \mathrm{Av}+33 \% \mathrm{Er}$; $50 \% \mathrm{Av}+50 \% \mathrm{Er} ; 33 \% \mathrm{Av}+67 \% \mathrm{Er} ; 100 \% \mathrm{Er}$. Os valores percentuais referem-se às quantidades de 80 e100 $\mathrm{kg} \mathrm{ha}^{-1}$ de sementes utilizadas na semeadura deervilhaca comum e aveia preta, respectivamente. O delineamento experimental utilizado foi o de blocos casualizados, dispostos em parcelas subdivididas, com quatro repetições. Os níveis de adubação nitrogenada foram locados nas parcelas principais e as espécies de inverno nas subparcelas.

As espécies de inverno foram plantadas em maio de1998 em SPD, em linhas espaçadas de 0,20 m. Nos sistemas de consórcios, as duas espécies foram semeadas na mesma linha. As sementes de ervilhaca foram inoculadas com rizóbio específico. As subparcel as com aveia receber am adubação nitrogenada de cobertura, aplicada a lanço na forma de uréia. As doses utilizadas foram de 60 e $30 \mathrm{~kg} \mathrm{ha}^{-1}$ de $\mathrm{N}$, respectivamente, para os tratamentos com $100 \%$ de aveia e para os sistemas consorciados de aveia e ervilhaca. A aplicação foi realizada em duas épocas, metade da dose, quando a planta deaveia estava no estádio de início do afil hamento, e metade com dois a três afilhos. Notratamento com $100 \%$ de ervilhaca, não foi realizada adubação nitrogenada. As espécies de cobertura foram dessecadas no estádio de plena floração da aveia preta, quando se aplicou a mistura dos her bicidas glyphosate e2,4-D, nas doses de 540 e $200 \mathrm{~g} \mathrm{ha}^{-1}$ de i.a., respectivamente.

Nove dias após a dessecação das espécies de cobertura de solo, fez-se a semeadura do cultivar de milho Pioneer 32R21, híbrido simples e de ciclo superprecoce. O milhofoi semeado em SPD, em linhas espaçadas de 0,7 m. Treze dias após a emergência das plântulas, foi real izado desbaste, ajustando-seà densidade de 62.000 plantas ha-1. $^{-1}$ A adubação de base consistiu da aplicação, em linha, de $120 \mathrm{~kg} \mathrm{ha}^{-1}$ de $_{2} \mathrm{O}_{5}$ (superfosfato triplo) e de $120 \mathrm{~kg} \mathrm{ha}^{-1}$ deK $_{2} \mathrm{O}$ (cloreto de potássio). A adubação nitrogenada variou deacordo com os níveis estabel ecidos. Nos tratamentos com 60 e $160 \mathrm{~kg} \mathrm{ha}^{-1}$ de N, aplicaram-se 30 kg ha-1 por ocasião da semeadura, sendo o restante parcelado em duas aplicações, com doses iguais, nos estádios de 3 a 4 e de 8 a 9 fol has expandidas. A cultura do milho recebeu suplementação hídrica por meio de irrigação por aspersão.

Nas espécies de cobertura de solo, avaliaram-se o rendimento individual de matéria seca da parte aérea e o total para as duas espécies, por meio da coleta da massa de cobertura em uma área de $0,25 \mathrm{~m}^{2}$ de cada subparcela. No milho, avaliou-se a quantidade de $\mathrm{N}$ absorvido por planta nos estádios de 3 a 4, 7 a 8, 10 a 11 folhas expandidas e de espigamento, pela multiplicação da produção de matéria seca por planta pelo teor de $\mathrm{N}$ no tecido. $\mathrm{O}$ teor de $\mathrm{N}$ foi determinado segundo método descrito em Tedesco et al. (1985). A produtividade de grãos de milho foi estimada pela extrapolação da produção da área útil da subparcela para um hectare, considerando a umidade padrão de $13 \%$. Os resultados obtidos foram submetidos às análises de variância e regressão.

\section{RESULTADOSE DISCUSSÃO}

\section{Rendimento de matéria seca das espécies de cobertura de solo}

Os rendimentos individuais de matéria seca (MS) de aveia preta e ervilhaca comum diminuíram à medida que se reduziram as suas proporções na semeadura nos sistemas consorciados (Figura 1). Na aveia preta, o decréscimo foi linear, com redução de $400 \mathrm{~kg} \mathrm{ha}^{-1}$ para cada $10 \%$ deredução na quantidade de semente utilizada, enquanto, para ervilhaca, a 
resposta seguiu model o quadrático.

Nos sistemas consorciados, a soma dos rendimentos de MS de aveia preta e ervilhaca comum foi similar à dos rendimentos da MS obtidos em seus cultivos isolados, com valores variando de 3,2 a 4 t ha $^{-1}$ (Figura 1 ). I sto evidencia que a utilização de ervil haca em consórcio com aveia preta não reduziu o rendimento de MS total da cobertura de solo. Assim, a utilização de sistemas consorciados, por aumentar a disponibilidade de $\mathrm{N}$ ao milho, pode diminuir as necessidades de apl icação de fertilizante nitrogenado sem influenciar a produtividade de grãos. Beutler et al. (1997) também evidenciaram o potencial de uso de sistemas consorciados de aveia e ervilhaca para obtenção de níveis adequados de matéria seca como cobertura de solo no inverno, tendo obtido na soma das produti vidades indi viduais 4,2 t ha-1 de matéria seca.

A capaci dade de produção de MS das espécies de cobertura de inverno é muito influenciada pelas condições ambientais, podendo ser utilizada como indicativo de sua adaptação ao local. Em trabalhos realizados por Heinrichs (1996), a equivalência na produção de matéria seca entre espécies ocorreu com a semeadura de $10 \%$ de sementes de aveia preta e $90 \%$ de ervilhaca comum em sistemas consorciados. Esse resultado foi atribuído à alta capacidade de competição da aveia preta, que dificulta o desenvolvimento de plantas de outras espécies em associação (Aita, 1997).

\section{Acúmulo de $\mathbf{N}$ por planta de milho}

Para esta variável não houve interação significativa de adubação nitrogenada aplicada no milho e proporção de sementes utilizadas na semeadura das espécies de cobertura de solo no inverno nos sistemas consorciados, em nenhum dos estádios avaliados.

$\mathrm{O} N$ acumulado por planta de milho reduziu-seà medida que diminuiu a adubação nitrogenada aplicada à cultura. Nos estádios iniciais de desenvolvimento da planta, houve pequena variação, dependendo das doses de N. Com a evolução do desenvolvimento da planta de milho, o acúmulo de $\mathrm{N}$ na fitomassa aumentou com a el evação da dose de N. Respostas semel hantes foram obtidas por Roman (1994); Da Ros \& Aita (1996) e Pöttker \& Clark et al. (1997b).

As diferentes proporções de sementes utilizadas na semeadura das duas espécies de cobertura desolo em sistemas consorciados não influíram na quantidade de $\mathrm{N}$ acumulado pela planta de milho cultivada em sucessão no estádio de 3-4 fol has (Figura 2). Isto pode ser atribuídoà baixa capacidade de absorção de $\mathrm{N}$ pelas plantas no início do desenvol vimento (Büll, 1993) eà baixa decomposição de resíduos das espécies de cobertura de solo decorrente do pouco tempo da dessecação.

Nos estádios de 7 a 8 fol has e de espigamento, a quantidade de $\mathrm{N}$ acumulado por planta de milho aumentou linearmente com o aumento da proporção de ervilhaca no consórcio. Para cada $10 \%$ de substituição de aveia por ervilhaca nos sistemas consorciados, a quantidade de $\mathrm{N}$ acumulado aumentou 18 e 42 mg planta-1 $^{-1}$, respectivamente, nos

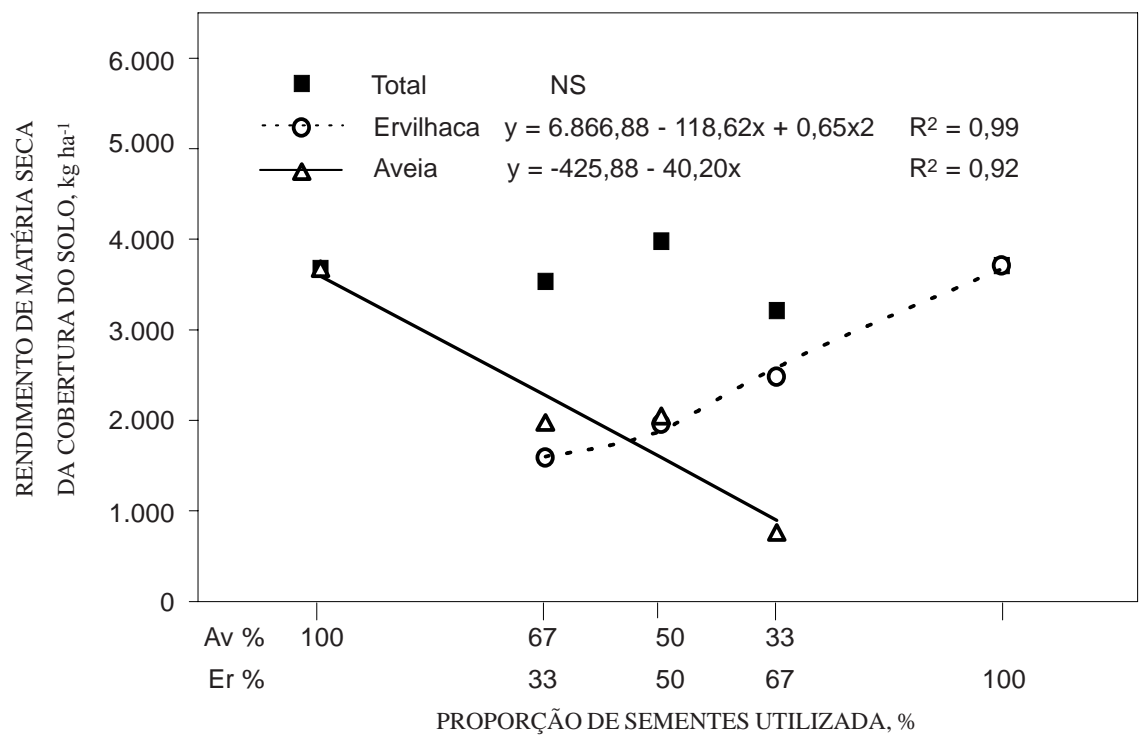

Figura 1. Rendimento individual de matéria seca de aveia preta (Av) e ervilhaca comum (Er) e rendimento total da cobertura de solo em três sistemas de consórcio e nos cultivos isolados. Eldorado do Sul (RS), 1998/99. * y = rendimento de matéria seca da cobertura de solo $\left(\mathrm{kg} \mathrm{ha}^{-1}\right)$, considerando $\mathrm{x} \% \mathrm{da}$ quantidade de sementes de aveia nos consórcios ou nos cultivos isolados. NS = não-significativo a $5 \%$. 
estádios de sete a oito folhas e de espigamento (Figura 2). No estádio de 10-11 fol has, observou-se resposta similar às verificadas nos estádios referidos anteriormente, porém a diferença só foi detectada a $7 \%$, possivelmente pel o mai or coeficiente de variação verificado (18\%) em relação ao observado nos estádios de sete a oito fol has e de espigamento.

Resultados semel hantes for am obtidos por Clark et al. (1997a), que determinaram menor acúmulo de $\mathrm{N}$ na planta de milho, quando cultivado após cevada, em relação à sucessão com ervilhaca, seja em cultivo isolado, seja em consórcio com cevada. O maior acúmulo de $\mathrm{N}$ na planta de milho obtido com o aumento na proporção de ervil haca como cobertura de solo no consórcio deveu-se à alta quantidade de $\mathrm{N}$ acumulado na fitomassa da leguminosa, que é disponibilizada ao sol o e aproveitada pel o mil ho em sucessão. A utilização de aveia preta como cobertura de sol o provocou imobilização de N, diminuindo sua disponibilidade no solo e absorção pela planta de milho (Pöttker \& Roman, 1994; Argenta, 1998).

\section{Produtividade de grãos de milho}

Houve interação de níveis de adubação nitrogenada aplicada no milho e proporção de sementes utilizadas na semeadura das duas espécies de cobertura de solo nos sistemas consorciados (Figura 3). Sem aplicação de N, a produtividade de grãos aumentou linearmente com o incremento da proporção de sementes de ervil haca nos sistemas de consórcio(Figura 3a). Para cada $10 \%$ de substituição de aveia por ervilhaca, houve incremento de $321 \mathrm{~kg} \mathrm{ha}^{-1}$ na produtividade de grãos. Com $60 \mathrm{~kg} \mathrm{ha}^{-1}$ de $\mathrm{N}$ aplicado no milho, a produtividade de grãos aumentou deforma quadrática, à medida queseelevou a proporção de ervilhaca no consórcio. Estimou-se que a máxima produtividade de grãos foi obtida quando o consórcio continha $84 \%$ deervilhaca e $16 \%$ de aveia. J á, com a aplicação da dose de 160 kg ha-1 de N no milho, a produtividade de grãos não variou, considerando a proporção de espécies de cobertura de sol o no inverno nos sistemas consorciados.

O incremento do nível de adubação nitrogenada aumentou linearmente a produtividade de grãos de milho, quando cultivado em sucessão à aveia, seja em cultivo isolado, seja consorciado com ervilhaca (Figura 3b). Por outro lado, quando o milho foi cultivado em sucessão à ervil haca em cultivo isol ado, não houve resposta da produtividade de grãos à adubação nitrogenada aplicada no milho.

Heinrichs et al . (1996) também observaram maior produtividade de grãos de milho quando cultivado sobre cobertura de $100 \%$ de ervilhaca, tendo-se reduzido à medida que aumentou a proporção de aveia nos consórcios. Os autores atribuíram ao aumento na produtividade de grãos em sucessão à ervilhaca a maior contribuição de $\mathrm{N}$ para aproveitamento do milho.

Da Ros \& Aita (1996) verificaram que a produtividade de grãos de milho plantado em sucessão à ervilhaca não respondeu à adubação nitrogenada. Por outrolado, quando cultivado sobre resíduos de aveia preta, foram observadas as maiores respostas ao $\mathrm{N}$ aplicado no milho. Isto foi atribuídoà menor disponibilidade de N no solo após aveia preta, possivelmente pela imobilização de $\mathrm{N}$ ocorrida no

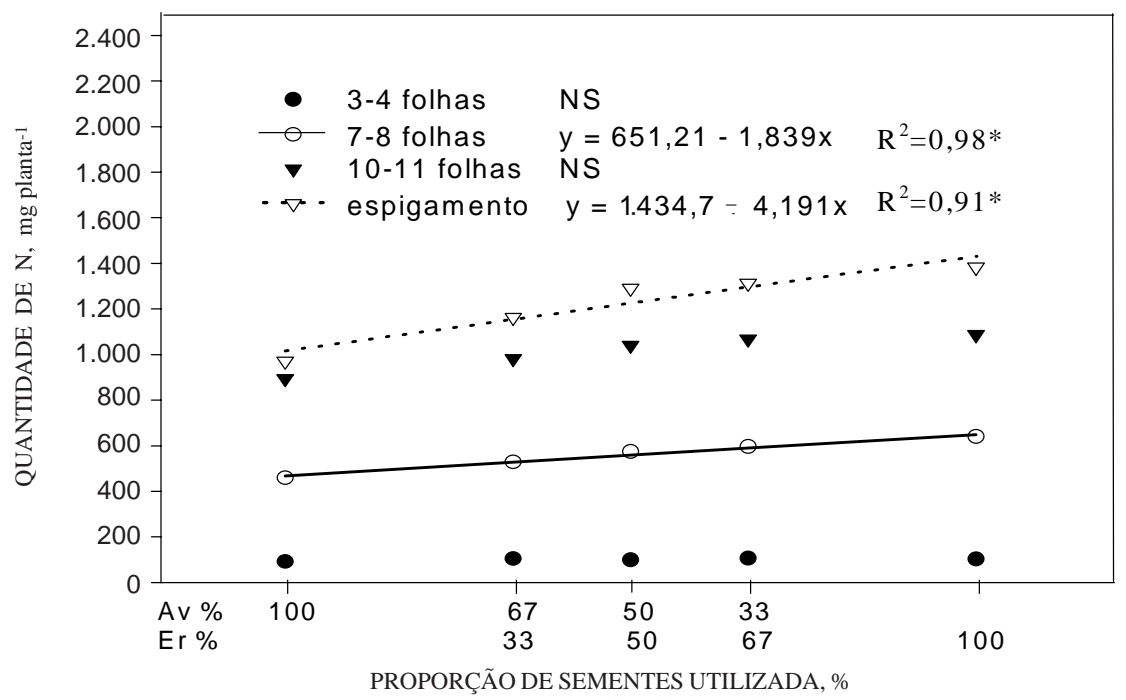

Figura 2. Quantidade de nitrogênio acumulado por planta nos estádios de 3 a 4, 7 a 8, 10 a 11 folhas expandidas e de espigamento do milho cultivado em sucessão à aveia preta (Av) e à ervilhaca comum (Er) em cultivos isolados e em consórcios, na média de três níveis de adubação nitrogenada aplicada no mi lho. E Idorado do Sul (RS), 1998/99. * y =Quantidade de $\mathrm{N}$ acumulado no mil ho (mg planta ${ }^{-1}$ ), considerando x\% da quantidade de sementes de aveia nos consórcios ou nos cultivos isolados. NS = não-significativo a $5 \%$. 


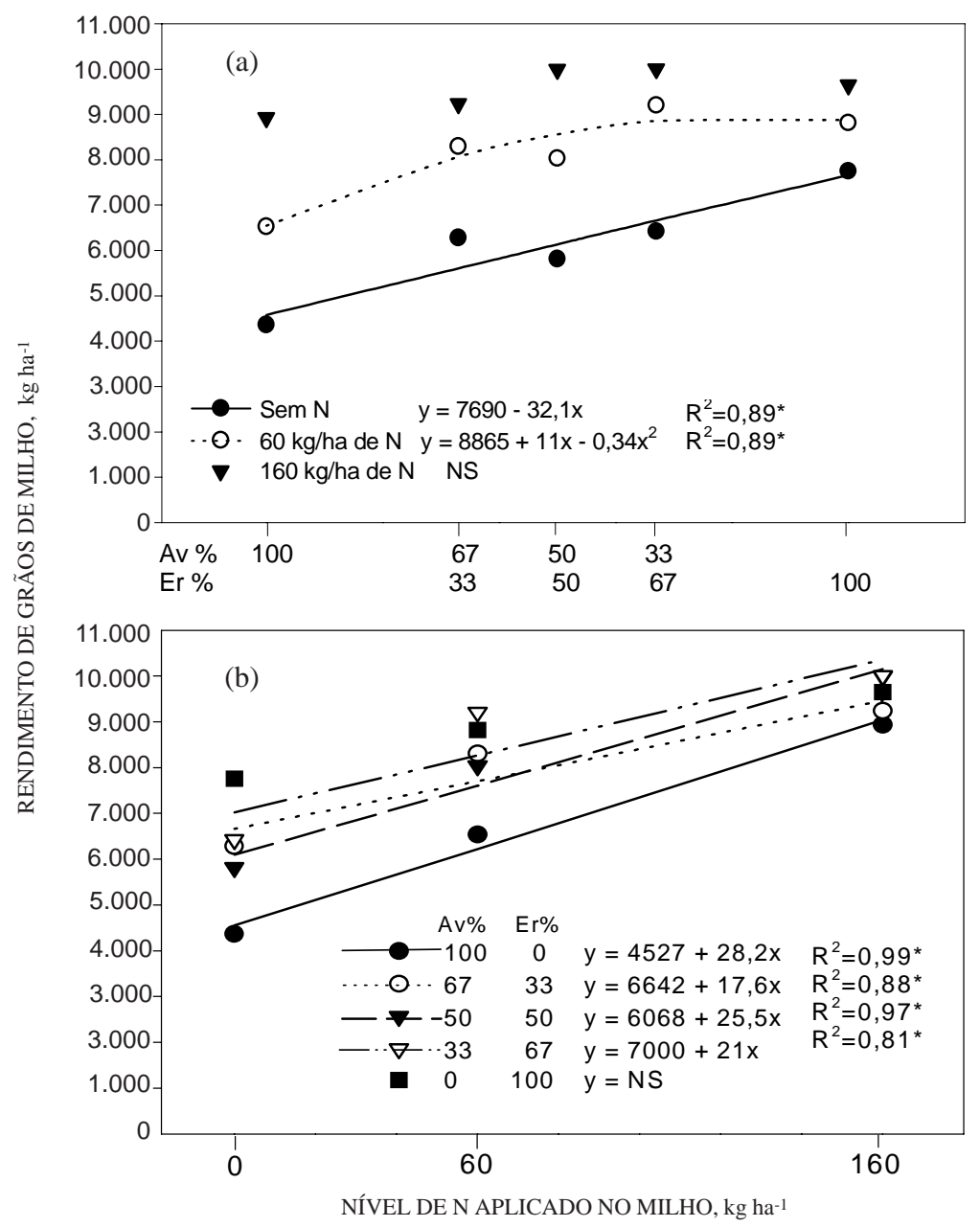

Figura 3. Produtividade de grãos de milho em sucessão à aveia preta (Av) e à ervilhaca comum (Er) em cultivos isolados e em consórcios como cobertura de solo sob três níveis de adubação nitrogenada (a) e das diferentes proporções de sementes utilizadas na semeadura de Av e Er em cobertura de solo, considerando os níveis de adubação nitrogenada (b). Eldorado do Sul (RS). 1998/99. y = produtividade de grãos de milho $\left(\mathrm{kg} \mathrm{ha}^{-1}\right)$, considerando $\mathrm{x} \%$ da quantidade de sementes de aveia nos consórcios ou nos cultivos isolados (A), considerando $x \mathrm{~kg} \mathrm{ha}^{-1}$ de nitrogênio aplicado no mi lho (B). NS = não-significativo a $5 \%$.

início de decomposição de seus resíduos.

Diversos autores evidenciaram que, sem apl icação de adubação nitrogenada, a produtividade degrãos de mil ho cultivado em sucessão aos sistemas consorciados de espécies leguminosas e gramíneas como cobertura de sol o foi maior do que a obtida em sucessão a coberturas de gramíneas em cultivo isolado (Beutler et al., 1997; Clark et al., 1997b; Vaughan \& Evanylo, 1998).

\section{CONCLUSÕES}

1. A utilização de ervilhaca comum em consórcio com aveia preta não reduziu o rendimento de matéria seca da cobertura de solo em relação ao cultivo isolado de aveia.

2. A introdução de ervilhaca em consórcio com aveia diminuiu a necessidade de adubação nitrogenada para o cultivo do milho em sucessão.

3. Com aplicação dealtas doses deadubaçãonitrogenada na cultura do mil ho cultivado em sucessão, as vantagens da utilização de ervil haca como cobertura desolo para fornecer nitrogênio não se manifestaram.

\section{LITE RATURA CITADA}

AITA, C. Dinâmica do nitrogênio no solo durante a decomposição de plantas de cobertura: efeito sobre a disponibilidade de nitrogênio para a cultura em sucessão. In: FRIES, M.R. \& DALMOLIN, R.S.D., coords. Atualização em recomendação de adubação e calagem: ênfase em plantio direto. Santa Maria, Pallotti, 1997. p.76-111. 
ARGENTA, G. Manejo do nitrogênio em milho implantado em semeadura direta, em dois ambientes, Porto Alegre, Universidade Federal do Rio Grande do Sul, 1998. 108p. (Tese de Mestrado)

BEUTLER, A.N.; ELTZ, F.L.F.; BRUM, A.C.R. \& LOVATTO, T. Fornecimento de nitrogênio por plantas de cobertura de inverno e de verão para o milho em sistema plantio direto. Ci. Rural, 27:555-560, 1997.

BÜLL, L.T. Nutrição mineral do milho. In: BÜLL, L.C., ed. Cultura do milho: fatores que afetam a produtividade. Piracicaba, POTAFOS, 1993. p.63-146.

CLARK, A.J .; DECKER, A.M.; MEISINGER, J .J . \& MCINTOSH, M.S. Kill date of rye, and a vetch-rye mixture: I. Cover crop and corn nitrogen. Agron. J ., 89:427-434, 1997a.

CLARK, A.J .; DECKER, A.M.; MEISINGER, J .J . \& MCINTOSH, M.S. Kill date of rye, and a vetch-rye mixture: II. Soil moisture and corn yield. Agron. J ., 89:434-441, 1997b.

DA ROS, A.O. \& AITA, C. Efeito de espécies de inverno na cobertura do solo e fornecimento de nitrogênio ao milho em plantio direto. R. Bras. Ci. Solo, 20:135-140, 1996.

DERPSCH, R. Importância da cobertura de solo e do preparo conservacionista. In: SIMPÓSIO DE MANEJ O DE SOLO E PLANTIO DIRETO NO SUL DO BRASI L, 1., SIMPÓSIO DE CONSERVAÇÃO DE SOLOS DO PLANALTO, 3., PaSSO Fundo, 1984, Anais. Passo Fundo, UPF/PIUCS/F aculdade de Agronomia, 1984. p.153-166.

EMPRESA BRASILEIRA DE PESQUISA AGROPECUÁRIA EMBRAPA. Centro Naiconal de Pesquisa de Solos. Sistema brasileiro de classificação de solos. Brasília, EMBRAPA, 1999. 412p..

HEINZMANN, F.X. Resíduos culturais de inverno e assimilação de nitrogênio por culturas de verão. Pesq. Agropec. Bras., 20:1021-1030, 1985.

HEINRICHS, R. Ervilhaca e aveia preta cultivadas simultaneamente como adubo verde e sua influência no rendimento do milho. Piracicaba, Escola Superior de Agricultura Luiz deQueiroz, 1996. 65p. (Tese de Mestrado)
HEINRICHS, R.; AMADO, T.J .C.; AITA, C. \& ZANCANARO, L. Consorciação de ervilhaca comum (Vicia sativa) e aveia preta (Avena strigosa) no fornecimento de nitrogênio e rendimento de milho. In: REUNIÃO CENTRO SUL DE ADUBAÇÃO VERDE E ROTAÇÃO DE CULTURAS, 4. Passo Fundo, 1994. Anais. PassoFundo, EMBRAPA-CNPT, 1994. 205p. (EMBRAPA-CNPT. Documentos, 14)

MONEGAT, C. Plantas de cobertura de solo: características e manejo em pequenas propriedades. Chapecó, Edição do Autor, 1991. 337p.

MUZILLI, O., OLIVEIRA, E.L.; GERAGE, A.C. \& TORNERO, M.T. Adubação nitrogenada em milho no Paraná. III. Influência da recuperação do solo com adubação verde de inverno nas respostas à adubação nitrogenada. Pesq. Agropec. Bras., 18:23-27, 1983.

PÖTTKER, D. \& ROMAN, E.S. Efeito deresíduos de cultura edo pousio de inverno sobre a resposta de milho a nitrogênio. Pesq. Agropec. Bras., 29:763-770, 1994.

SÁ, J .C.M. Manejo do nitrogênio na cultura do milho no sistema plantio direto. In: FANCELLI, A.L. \& DOURADO-NETO, D., eds. Tecnol ogia da produção de milho. Piracicaba, Escola Superior de Agricultura Luiz de Queiroz, 1997. p.84-103.

SÁ, J .C.M. Manejo do nitrogênio na cultura do milho no sistema plantio direto. Passo Fundo, Aldeia Norte, 1996. 24p.

SANGOI , L.; ERNANI, P.R.; RAMPAZZO, C.; GRACIETTI, L.C. \& KONFLANZ, V.A. Dinâmica do nitrogênio no solo em função do manejo da palha e da forma de aplicação do fertilizante nitrogenado. In: REUNIÃO TÉCNICA CATARINENSE: MILHO \& FEIJ ÃO, 2., Lages, 1999. Resumos. Lages, UDESC/EPAGRI, 1999. v.1. p.213-218.

TEDESCO, M.J .; VOLKWEISS, S.J . \& BOHNEN, H. Análise de solo, plantas e outros materiais. PortoAlegre, Universidade Federal do Rio Grande doSul, 1985. 188p. (Boletim Técnico, 5)

VAUGHAN, J .D. \& EVANYLO, G.K. Corn responseto cover crop species, spring desiccation time, and residue management. Agron. J ., 90:536-544, 1998. 
C. G. BORTOLINI et al. 